\title{
THE EFFECTIVENESS OF BILATERAL GREATER OCCIPITAL NERVE BLOCK BY ULTRASOUND FOR TREATMENT OF POST-DURAL PUNCTURE HEADACHE IN COMPARISON WITH OTHER CONVENTIONAL TREATMENT
}

\author{
By
El-Sayed Mostafa Mohamed Stohy, Mostafa Mohamed Mohamed El- Sayed and Mohamed Saeed Mohamed Bastawesy

Department of Anesthesiology and Intensive care Department, Faculty of Medicine, AlAzhar University

E-mail: mahammedsaeed5100@gmail.com

\begin{abstract}
Background: Headache is one of the frequent human pains and it may indicate serious disease or represent only tension, exhaustion, or a migrainous disorder.

Objectives: The purpose of this study is to evaluate the effectiveness of ultrasound-guided bilateral greater occipital nerve blockade for the treatment of PDPH in patients underwent spinal anesthesia by bilateral injection of lidocaine $2 \% 40 \mathrm{mg}$ and dexamethasone $8 \mathrm{mg}$ in a total volume of $4 \mathrm{~mL}$.

Patients and Methods: The ethics committee at Al-Azhar University approved this prospective randomized clinical study, and patients written informed consent was obtained. The study was carried out at Al- Azhar University Hospitals (Al-Hussein and Bab El-Sharia). This study included 50 patients of both genders, admitted for spinal anesthesia carried out at Al- Azhar University Hospitals (El-Hussein and Bab ElSharia).They were randomly allocated into two equal groups:
\end{abstract}

Group (A): Patients received bilateral injection of lidocaine $(40 \mathrm{mg})$ and dexamethazone $(8 \mathrm{mg})$ in a total volume of $4 \mathrm{~mL}$. Injection were done by ultrasound (sonosite) using the linear probe. Block and assessment were done. Using linear probe, $22 \mathrm{G}$ needle used at depth less than $2 \mathrm{~cm}$ until greater occipital artery was visualized as a landmark, then local anesthetics were injected medially and surrounding the artery.

Group (B): Patients received conventional treatment such as (bed rest, hydration, Acetaminophen, Caffeine, NSAIDs and opioids).

In both groups: We gave $25 \mathrm{mg}$ pethidine to control surgical pain

If visual analogue scale (VAS) was greater than 4, Acetaminophen, Caffeine, NSAIDs and opioids were given.

Results: Regarding the requirement of analgesia, there was a significant statistical difference between the two groups. In the injection group, There was significant statistical difference in headache intensity between the two groups at 1,6 and $12 \mathrm{~h}$ after the injection, 8 out of 25 patients only needed analgesia in the form of paracetamol and NSAI (ketorolac, $30 \mathrm{mg}$ ), while in the medical group all 25 patients needed analgesia in form of (paracetamol) and NSAI(ketorolac 30mg). Regarding the total dose of paracetamol, there was a significant statistical difference between the two groups. Regarding the total dose of NSAIDs (ketorolac), there was no significant statistical difference between the two groups.

Conclusion: Bilateral ultrasound-guided injection of GON block is an easy, minimally invasive, easy and cost-effective technique and may be considered before the utilization of a blood patch. 
Keywords: Effectiveness, Bilateral Greater Occipital Nerve Block, Ultrasound, Post-Dural Puncture Headache.

\section{INTRODUCTION}

Post-dural puncture headache (PDPH) is a distressing obstacle of neuraxial anesthesia and comes about approximately $1.5 \%$ of cases ranging from $0.19 \%$ to $3.6 \%$ in different units. A possible treatment method for PDPH is the GON blockade. The analgesia experienced after the block can be understood by the core neuromodulatory influence which induces reduced central sensitization as a consequence of the transient disruption of afferent feedback into the dorsal roots or trigeminal nucleus. It is not clear whether, given the etiology, the migraine has stopped unequivocally. Reducing nociceptive traffic in sensitization can occur through a temporary neural blockade (Akyol et al., 2015).

The first post-dural puncture headache (PDPH) is considered one of the commonest causes of morbidity following neuraxial anesthesia that may increase the period of hospital stay and is considered a major cause of increased anesthetic workload (Bezov et al., 2010).PDPH is usually simple and self-limited, but if left untreated, it may lead to more serious complications (Lavi et al., 2010).

The mechanism of PDPH is still unclear. The postulated cause of the headache is a reduction of cerebrospinal fluid pressure due to the leak of cerebrospinal fluid in the epidural space through the dural puncture site. Decreased CSF pressure creates a reduction of the cushioning effect normally provided by intracranial fluid. The resulting traction placed on intracranial pain-sensitive structures triggers pain. A second possible cause is the distension of the cerebral blood vessels. With a rapid decrease in cerebrospinal fluid pressure, vasodilation of the intracranial vessels occurs to maintain a constant intracranial volume, resulting in pathophysiology similar to a vascular headache. Post dural puncture headache presents as a dull throbbing pain with a frontal-occipital distribution. Typically, the headache is increased by an upright position and decreased by lying down. The diagnosis should be questioned in the absence of a postural component of the headache. At least partial improvement should occur when the patient assumes the supine position. According to the international classification of headache disorders criteria for the diagnosis of PDPH, headache emerges within 5 days after dural puncture and disappears spontaneously within 1 week or up to $48 \mathrm{~h}$ after an epidural blood patch. The headache may appear with neck stiffness, tinnitus, photophobia, and nausea (Amorim et al., 2012).

Once Post-dural-puncture headache happens, several conservative therapies are commonly used, such as hydration and bed rest. These therapies aim to decrease CSF loss through the dural hole and restore CSF with additional fluid intake,but these measures have a history of not being very effective. So, intervention treatment should not be delayed in order to avoid suffering. There are several modalities available for the treatment of PDPH. One of these is epidural blood patch (EBP) which has 
THE EFFECTIVENESS OF BILATERAL GREATER OCCIPITAL NERVE... 481

shown to be very effective as an interventional treatment, but it is more or less invasive and not accepted by many patients. There are many drugs used for the treatment of PDPH such as gabapentin, hydrocortisone, cosyntropin (ACTH), sumatriptan, caffeine, Nonsteroidal anti-inflammatory drug (NSAIDs) and morphine (Baysinger et al., 2011).

The purpose of this study was to evaluate the efficacy of ultrasound-guided bilateral greater occipital nerve blockade for treatment of PDPH in patients undergoing spinal anesthesia by bilateral injection of lidocaine $(40 \mathrm{mg})$ and dexamethasone $(8 \mathrm{mg})$ in a total volume of $4 \mathrm{~mL}$. The severity of headache was considered as primary outcome, and the total consumption of analgesic, recurrence of headache and advesre effect was considered as secondary outcome.

\section{PATIENTS AND METHODS}

The ethics committee at Al-Azhar University Hospitals (Al-Hussein and Bab El-Sharia) approved this prospective randomized clinical study. Patients' written informed consent was obtained. This study was carried out during the period from October, 2018 to June, 2019.

This study included 50 patients of both sexes, admitted for spinal anesthesia. They were randomly allocated into two equal groups:

Group (A): received a bilateral injection of lidocaine $(40 \mathrm{mg})$ and dexamethasone $(8 \mathrm{mg})$ in a total volume of $4 \mathrm{~mL}$ during 24 hours of appearing of headache. The injection was done by ultrasound using the linear probe.
Group (B): received conventional treatment during 24 hours of appearing of headache such as (bed rest, hydration, Acetaminophen (1 gm) every 8 hours, NSAIDs (ketolac, 30 $\mathrm{mg}$ ) repeated if headache intensity $>4$ up to $60 \mathrm{mg}$.

We gave pethidine $(25 \mathrm{mg})$ to control surgical pain if patient VAS was greater than 4 after injection Acetaminophen, Caffeine, NSAIDs and opioids were given.

The sample size was calculated according to Kamala et al. (2014).

\section{Inclusion criteria:}

- Patients expressing PDPH after spinal anesthesia with $22 \mathrm{G}$ needle.

\section{Exclusion criteria:}

- Refusal of the patient.

- Patients with chronic headache or migraine.

- Hypertensive patients.

- A patient that cannot comply with the VAS.

Severity of headache was assessed subjectively using $10 \mathrm{~cm}$ VAS where zero means no pain and 10 is the worst possible pain of the severity of headache at 1, 2, 4, 6, 12, 24 hours after injection. Secondary outcome: total consumption of analgesic (paracetamol, NSAI), recurrence of headache and adverse effects Vasovagal syncopal attack, transient light headedness following the injection, intravascular injection of the local anesthetic solution were also assessed. 


\section{Statistical analysis:}

Recorded data were analyzed using the statistical package for social sciences, version 20.0 (SPSS Inc., Chicago, llinois, USA). Quantitative data were expressed as meant standard deviation (SD). Qualitative data were expressed as frequency and percentage.

\section{The following tests were done:}

- Independent-samples t-test of significance was used when comparing between two means.
- Mann Whitney U test: for two-group comparisons in non-parametric data.

- Chi-square (x2) test of significance was used in order to compare proportions between qualitative parameters.

- The confidence interval was set to 95\% and the margin of error accepted was set to $5 \%$. So, the p-value was considered significant as the following:

- P-value <0.05 was considered significant.

\section{RESULTS}

There was no statistical significant difference between the two groups according to demographic data, and the time of appearance of headache.There was a significant statistical difference between groups according to paracetamol dose in the GONB group $(2.88 \pm 0.83)$ and in the medical group $(3.72 \pm 0.46)$ (pvalue $<0.001$ ). No statistical difference between the two groups according to the NSAI dose (Table 1).

Table (1): Demographic data of the two groups

\begin{tabular}{|c|c|c|c|c|}
\hline Parameters Groups & $\begin{array}{c}\text { Greater occipital nerve block } \\
\text { group (N=25) }\end{array}$ & $\begin{array}{c}\text { Medical group } \\
(\mathbf{N = 2 5})\end{array}$ & $\begin{array}{c}\text { p- } \\
\text { value }\end{array}$ \\
\hline \multirow{2}{*}{ Sex } & Male & $37.4 \pm 11.79$ & $33.72 \pm 8.2$ & $>0.05$ \\
\cline { 2 - 4 } & Female & 6 & 5 & \multirow{2}{*}{$>0.05$} \\
\hline \multicolumn{2}{|c|}{ Obstetric surgery } & 19 & 20 & \multirow{2}{*}{$>0.05$} \\
\hline \multicolumn{2}{|c|}{ Non obstetric surgery } & 18 & 17 & \multirow{2}{*}{$>0.05$} \\
\hline $\begin{array}{c}\text { Time till appearance of } \\
\text { headache (hours) }\end{array}$ & $28.12 \pm 6$ & $27.44 \pm 6.3$ & $<0.001$ \\
\hline Paracetamol dose (gm) & $2.88 \pm 0.83$ & $3.72 \pm 0.46$ & $>0.05$ \\
\hline \multicolumn{2}{|c|}{ NSAI dose (mg) } & $35 \pm 12.2$ & $40 \pm 14.64$ & \multicolumn{2}{c}{} \\
\hline
\end{tabular}

Mann Whitney U test was used in table (1)

There was a significant statistical difference in headache intensity between the two groups at 1,6 and $12 \mathrm{~h}$ after the injection. There was a significant difference between the two groups according to VAS as (Table 2). 
THE EFFECTIVENESS OF BILATERAL GREATER OCCIPITAL NERVE... 483

Table (2): Comparison between the two groups according to visual analog scale(VAS)

\begin{tabular}{|l|c|c|c|}
\hline VAS & $\begin{array}{c}\text { Greater occipital } \\
\text { nerve block group } \\
(\mathbf{N = 2 5 )}\end{array}$ & $\begin{array}{c}\text { Medical group } \\
(\mathbf{N = 2 5 )}\end{array}$ & P-value \\
\hline Intial & $6(5-8)$ & $6(5-8)$ & $>0.05$ \\
\hline $\mathbf{1}^{\text {st }}$ hour & $2(0-5)$ & $5(3-7)$ & $<\mathbf{0 . 0 0 1}$ \\
\hline $\mathbf{2}^{\text {nd }}$ hour & $1(1-3)$ & $3(2-5)$ & $>0.05$ \\
\hline $\mathbf{4}^{\text {th }}$ hour & $2(1-5)$ & $3(1-6)$ & $>0.05$ \\
\hline $\mathbf{6}^{\text {th }}$ hour & $2(1-4)$ & $3(1-5)$ & $\mathbf{0 . 0 0 1}$ \\
\hline $\mathbf{1 2}^{\text {th }}$ hour & $2(1-3)$ & $3(1-5)$ & $\mathbf{0 . 0 0 7}$ \\
\hline $\mathbf{2 4}^{\text {th }}$ hour & $2(1-3)$ & $3(2-4)$ & $>0.05$ \\
\hline
\end{tabular}

Mann - whitney U test was used in table (2)

Recurrence of headache occurred in greater occipital nerve block. There were six patients in greater occipital nerve

\section{DISCUSSION}

In group A VAS showed a significant statistical reduction in headache intensity at one, 6 and $12 \mathrm{~h}$ after the injection. But in 2 and 4, they had insignificant lower VAS than medical group. This was accompanied by a significant statistical reduction in total analgesic consumption in paracetamol, and no significant effect of ketorolac between the two groups.

The result of this study coincided with Kamala et al. (2014) who showed that bilateral GONB relieved the PDPH in a shorter time with lower analgesic consumption and earlier patient discharge home in comparison with traditional medical treatment.

The present work denotes that it was agreed with Levin (2010), Takmaz et al. (2010), Niraj et al. (2014), Akyol et al. (2015), Lauretti et al. (2015), Türkyilmaz. et al. (2016), and Allen et al. (2018) also reported the effect of bilateral GON blockage on PDPH. headache was recurred. There was no adverse effect in this study.

\section{LIMITATIONS}

1. This research was carried out without a comparative group using systemic steroids in the form of hydrocortisone versus the local steroid injection we used in this study.

2. We have assessed the headache for only 24 hours and it might have recurred after that.

\section{CONCLUSION}

Bilateral ultrasound-guided injection of GON block was a minimally invasive, easy and effective method and may be considered before the application of a blood patch. Dexamethasone-lidocaine mixture was better than medical treatment in reducing the severity of PDPH inpatient.

\section{REFERENCES}

1. Akyol, F., Binici, O., Kuyrukluyildiz, U., and Karabakan, G. (2015): Ultrasoundguided bilateral greater occipital nerve block for the treatment of post-dural puncture headache. Pakistan Journal of Medical Sciences, 31(1): 111-115. 
2. Allen, S. M., Mookadam, F., Cha, S. S., Freeman, J. A., Starling, A. J., and Mookadam, M. (2018): Greater occipital nerve block for acute treatment of migraine headache: a large retrospective cohort study. The Journal of the American Board of Family Medicine, 31(2):211-218.

3. Amorim, J. A., Gomes de Barros, M. V., and Valença, M. M. (2012): Post-dural (post-lumbar) puncture headache: risk factors and clinical features. Cephalalgia, 32(12), 916-923.

4. Baysinger, C. L., Pope, J. E., Lockhart, E. M., and Mercaldo, N. D. (2011): The management of accidental dural puncture and postdural puncture headache: a North American survey. Journal of clinical anesthesia, 23(5): 349-360.

5. Bezov, D., Lipton, R. B., and Ashina, S. (2010): Post-dural puncture headache: part I diagnosis, epidemiology, etiology, and pathophysiology. Headache: The Journal of Head and Face Pain, 50(7): 1144-1152.

6. Kamala, S. M., Hassan, G. A. and Wahba, S. S. (2014): Management of postdural puncture headache: greater occipital nerve block technique. Ain-Shams Journal of Anaesthesiology, 7(1): 25-31.

7. Lauretti, G. R., Corrêa, S. W. and Mattos, A. L. (2015): Efficacy of the greater occipital nerve block for cervicogenic headache: comparing classical and subcompartmental techniques. Pain Practice 15(7): 654-661.

8. Lavi, R., Rowe, J. M. and Avivi, I. (2010): Lumbar puncture: it is time to change the needle. European neurology, 64(2): 108-113.

9. Levin, M. (2010): Nerve blocks in the treatment of headache. Neurotherapeutics, 7(2): 197-203.

10. Niraj, G., Kelkar, A., and Girotra, V. (2014): Greater occipital nerve block for postdural puncture headache (PDPH): a prospective audit of a modified guideline for the management of PDPH and review of the literature. Journal of Clinical Anesthesia, 26(7):539-544.

11. Takmaz A, S., Kantekin U, C., Kaymak C. and Başar, H. (2010): Treatment of postdural puncture headache with bilateral greater occipital nerve block. Headache: The Journal of Head and Face Pain, 50(5): 869872.

12. Türkyilmaz, E. U., Eryilmaz, N. C., Güzey, N. A. and Moraloğlu, Ö. (2016): Bilateral greater occipital nerve block for treatment of post-dural puncture headache after caesarean operations. Revista Brasileira de Anestesiologia, 66(5):445-450. 


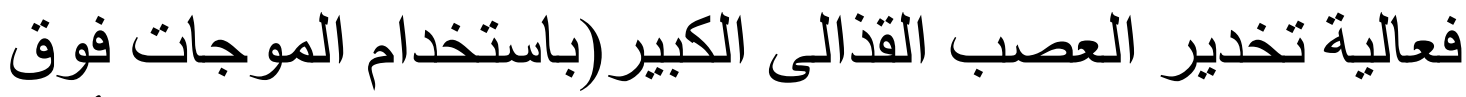

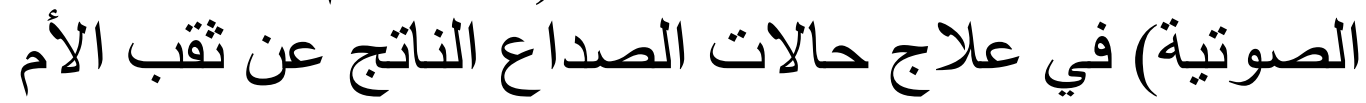 الجاقيه مقارنة بالعلاج الاته التقليدى}

السيد مصطفى محمد سطوحى، مصطفي محمد محمد السيد، محمد سعيد محمد بسطوبسي

قسم التخديرو الرعايه المركزة، كلية الطب الأزهر

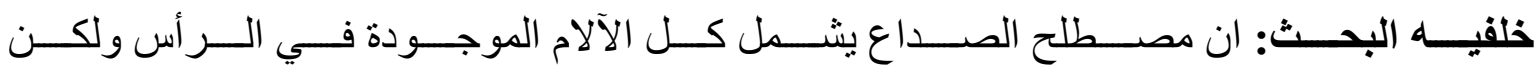

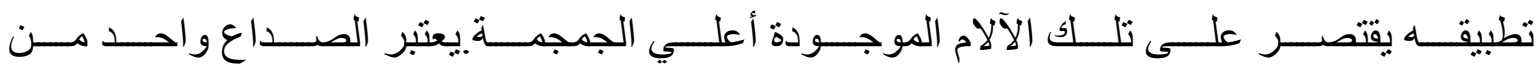

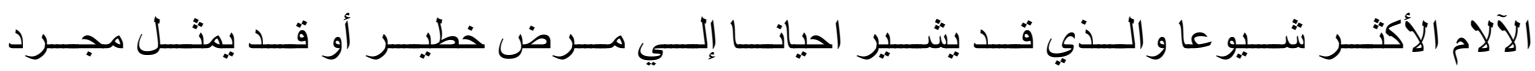
تونر، أو إرهاق، أو ما يسمي بالصداع النصفي.

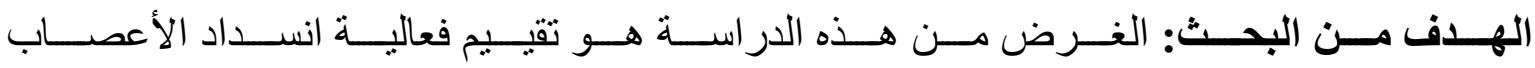

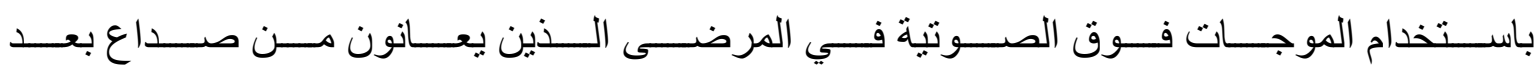

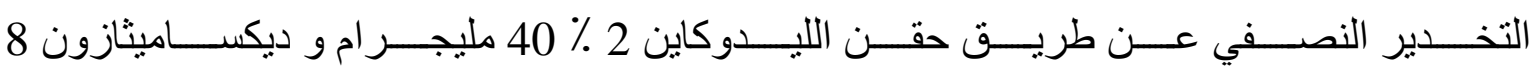
مليجر ام في حجم إجمالي 4 ملليتر.

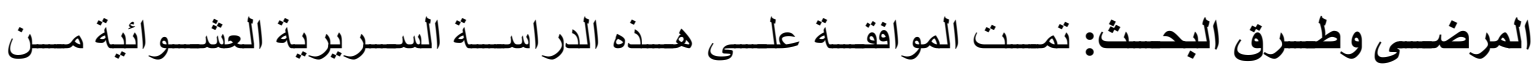

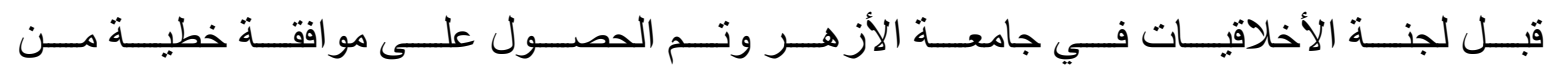

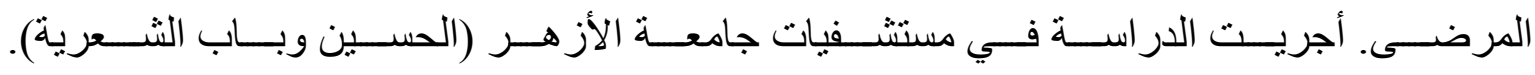
شملت هذه الدر اسة 50 مريضا من كلا الجنسين ، وتم خضو عهم للتخدير النصفى.

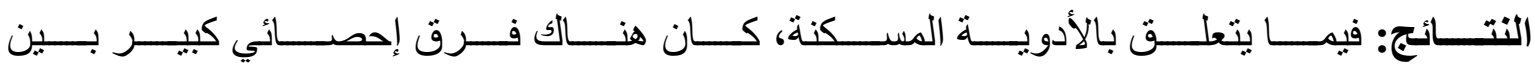

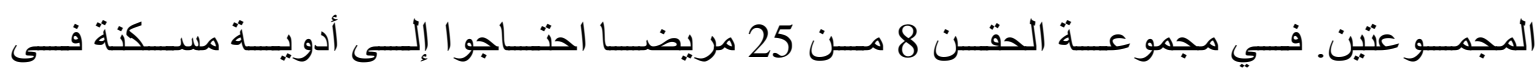

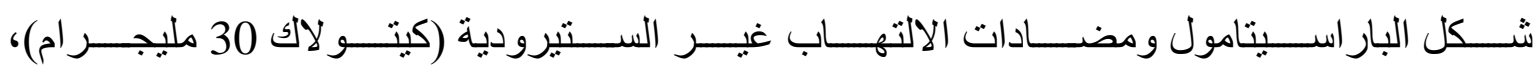

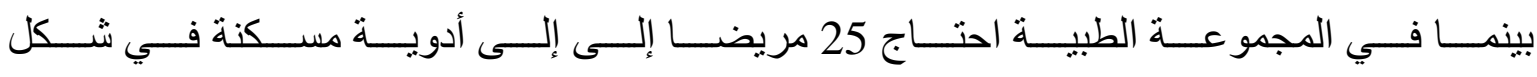

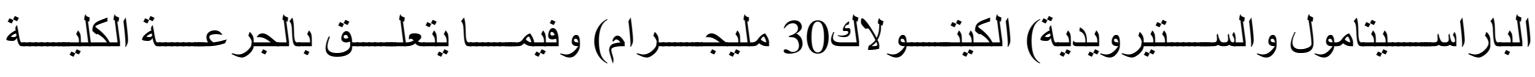

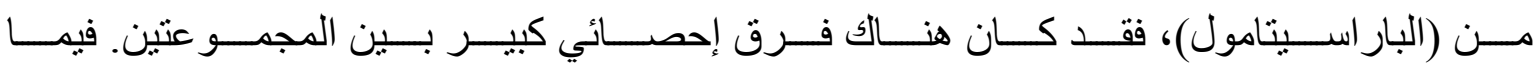




\section{EL-SAYED MOSTAFA MOHAMED STOHY et al.,}

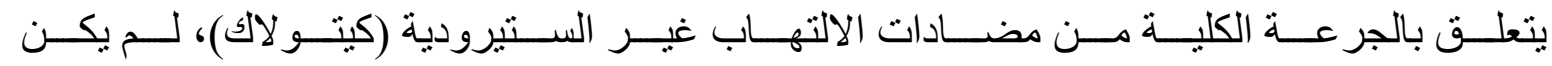
هناك فرق إحصائي كبير بين المجمو عتين.

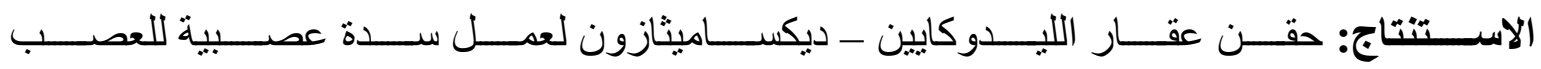

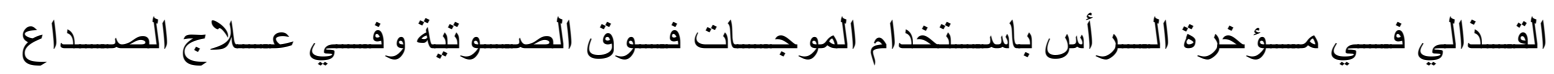

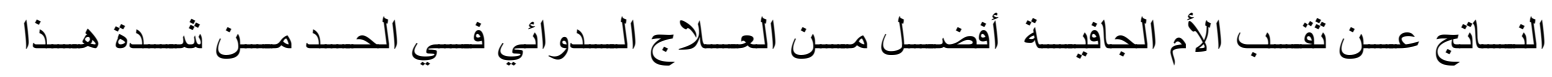
الصداع لدي هؤلاء المرضى. 